\title{
Carlos V y Lutero en el espejo: la Dieta de Worms (1521) en la historiografía española del siglo XVI
}

\author{
Francisco Bautista \\ Universidad de Salamanca \\ francisco.bautista@usal.es
}

Recepción: 30/04/2019, Aceptación: 19/05/2019, Publicación: 04/12/2019

\begin{abstract}
Resumen
Este trabajo proporciona un estudio crítico de las narraciones en torno al encuentro entre Carlos V y Lutero en el curso de la Dieta de Worms (1521). Este hecho, que tuvo una especial repercusión en la ruptura de Lutero con Roma y en los problemas políticos del Emperador en Alemania, fue narrado por diversos intelectuales e historiadores espańoles a lo largo del siglo xvi. Aquí se analizan los relatos escritos al calor de los hechos, y también su posición en las historias sobre Carlos $\mathrm{V}$ producidas en la segunda mitad del siglo XVI, atendiendo sobre todo a las piezas menos conocidas o inéditas.
\end{abstract}

Palabras clave

historiografía; testimonio; imprenta; manuscritos; luteranismo; contra-historia

\begin{abstract}
Carlos V and Luther in the mirror: The Diet of Worms (1521) in Spanish historiography of the 16th century

This article provides a critical study of the narrative accounts about the meeting between Charles V and Luther in the course of the Diet of Worms (1521). This event, which had a special impact on Luther's break with Rome and on the political problems of the Emperor in Germany, was narrated by various Spanish intellectuals and historians throughout the 16th century. Here the stories written in the heat of the facts are analyzed, as well as histories about Carlos V produced in the second half of the 16th century, paying special attention to the less known or unpublished pieces.
\end{abstract}

\section{Keywords}

historiography; testimony; printing; manuscripts; Lutheranism; counter-history 


\section{Introducción}

La comparecencia de Lutero ante Carlos V en el curso de la Dieta de Worms (1521) no solo significó un hito importante en el itinerario de la ruptura del teólogo agustino con Roma y en el desarrollo del luteranismo, sino que marca también la primera intervención de Carlos $\mathrm{V}$ en un conflicto cuyas repercusiones políticas se proyectarían sobre el conjunto de su largo gobierno. Aunque el episodio de Worms es bien conocido, valdrá la pena recordar aquí los datos esenciales, con una breve contextualización, ya que ello servirá al análisis de los textos y fragmentos sobre los que trato a continuación. Tras la publicación de las famosas Noventa y cinco tesis en 1517, el papa León X hubo de intervenir para tratar de que Lutero se retractase de ciertas opiniones emitidas en ellas, en particular sobre las indulgencias. Llamado a presentarse ante el legado pontificio, el cardenal Tomás Cayetano (1469-1534), durante la Dieta de Augsburgo, presidida por el emperador Maximiliano, Lutero evitó rectificar en el curso de tres comparecencias celebradas entre los días 12 y 15 de octubre de 1518 . Ese encuentro termina entonces sin ningún tipo de compromiso, y Lutero huye de Augsburgo ante el temor a ser apresado. El 15 de junio de 1520 se publica la bula Exsurge Domine, que, aunque aún no excomulga a Lutero, le conmina a abandonar sus enseñanzas ajenas a la doctrina católica. Lejos de surtir efecto, a lo largo de 1520 Lutero da a conocer varias obras en las que eleva el tono contra Roma y radicaliza sus propias posiciones, que afectan a aspectos centrales de la doctrina romana, como la confesión, la creencia en el Purgatorio o, con algunos matices, el culto de los santos. La respuesta del Papado no se hace esperar, y el 3 de enero de 1521 aparece la bula Decet Romanum Pontificum, donde se decreta la excomunión de Lutero. Es en este contexto, en la antesala de la Dieta de Worms, que se extendió del 28 de enero al 25 de mayo, y con la que se inauguraba el gobierno imperial de Carlos $\mathrm{V}$, en el que se llevaron a cabo las gestiones para que el Emperador aceptase recibir a Lutero e interviniese en su disputa con Roma. La presencia de Lutero no formaba parte de las discusiones oficiales en la Dieta, que se centrarían en asuntos de gobierno y cuestiones fiscales. Sin embargo, Carlos accedió a la petición del elector Federico de Sajonia (1463-1525), entre otros, de escuchar a Lutero antes de asumir la condena papal.

La llegada de Lutero a Worms tuvo lugar el 16 de abril, en un clima de amplia expectación, y con muchos partidarios a su lado. Compareció ante el Emperador en la tarde del día siguiente, y junto a unos libros suyos dispuestos sobre una mesa se le preguntó si reconocía su autoría y si se reafirmaba o se retractaba de lo que en ellos había escrito. Lutero dijo ser el autor de los textos, pero ante la trascendencia de la segunda pregunta solicitó un poco de tiempo para responder con seguridad. Al día siguiente, de nuevo en la tarde, Lutero declaró que se reafirmaba en lo publicado, hasta que alguien le convenciera de sus errores con la autoridad de la Biblia, diciendo que no quería mentir ni actuar contra su conciencia. Con las palabras de Lutero se puso fin a su comparecencia, y se diluía 
la posibilidad de encontrar una solución rápida o sencilla, lo que hizo que la mediación del Emperador resultase prácticamente inútil. El 19 de abril, Carlos $V$ leyó una declaración ante los electores en la que subrayaba su compromiso con la fe católica y con la defensa de la unidad de la cristiandad. Aun así, todavía en los días siguientes diversas personalidades del círculo imperial trataron sin éxito de arrancar algún tipo de concesión por parte de Lutero. Protegido por el salvoconducto que Carlos V le había concedido, Lutero abandonó Worms el 26 de abril, y pocos días después, el 4 de mayo, tuvo lugar la ficción de un asalto, que le permitió refugiarse en el castillo de Wartburg para poder sortear la sentencia de destierro que el Emperador ya había anunciado. El 25 de mayo Carlos V promulgó el llamado Edicto de Worms por el que se proscribía a Lutero y se prohibía la difusión y la lectura de sus textos. ${ }^{1}$

Puede decirse que el episodio de Worms acabó siendo una demostración de fuerza del teólogo y de sus partidarios, y que el escenario de la corte imperial fue hábilmente aprovechado para dar una mayor resonancia a la propia figura de Lutero y a sus ideas. No es extraño, por tanto, que existan numerosas relaciones sobre este episodio, que circularon además con profusión desde muy pronto. Los personajes envueltos en estos hechos, con un joven Carlos que comenzaba su mandato imperial en medio de favorables auspicios y con un Lutero como estrella ascendente en la polémica religiosa, y los propios hechos, que se cierran con la desaparición novelesca del agustino, contribuyeron a acentuar la resonancia de lo acaecido en Worms. Vista esa expectación, tampoco debe sorprender que se redactasen diversos relatos testimoniales por intelectuales españoles que formaban parte del séquito imperial. Estas narraciones inauguran la inscripción de la comparecencia de Lutero ante Carlos V en la memoria histórica sobre este último, aunque solo sea en principio de forma virtual, al estar desligados de un marco más amplio sobre los hechos del Emperador.

En este sentido, es interesante notar que, ante la escasez de la presencia de Lutero en obras hispánicas de tipo histórico, será justamente el episodio de Worms uno de los escasos momentos en los que el teólogo agustino emerge en los textos, o al menos aquel en torno al cual se articulan otras menciones. En cierta medida, no solo era tentador, sino casi inevitable, ya que tal fue el único momento en el que los itinerarios de ambos personajes coincidieron en el tiempo y el espacio. Al intervenir en el conflicto religioso, Carlos lo hacía ejerciendo sus facultades imperiales, como él mismo manifestó en su declaración del 19 de abril y en el posterior Edicto de Worms, de modo que al narrar su vida resultaba esperable tocar este asunto. Sin embargo, el diverso tratamiento que el episodio recibió en las varias obras históricas sobre Carlos V escritas a lo largo del siglo XVI sugiere que fue visto como un locus historiográfico particularmente

1. Para una detallada exposición sobre la Dieta de Worms, puede verse García-Villoslada (19731976: I, 527-582). 
controvertido o problemático. Desde la concentración estricta en los hechos a la contextualización, siquiera mínima, de las ideas de Lutero, desde la supresión de este encuentro a la consolidación estereotipada del mismo, en base a los textos canónicos antiluteranos y su adaptación hispánica, la propia variación muestra la dificultad de la corte imperial o de los historiadores de Felipe II para articular una respuesta en términos de imagen y de memoria. A lo largo de este trabajo, se tratará de ofrecer un análisis de los principales textos quinientistas, atendiendo también a su difusión e impacto. Para ello, me centraré primero en los relatos de tipo testimonial para pasar luego a las obras propiamente históricas, tanto aquellas compuestas al final del reinado de Carlos V como las producidas durante la época de Felipe II. ${ }^{2}$

\section{«Habes rem fidelissime descriptam». Testimonios hispánicos sobre Worms}

Los textos que conocemos sobre Worms compuestos por testigos presenciales o que se escribieron a partir de informes de personas que se encontraron presentes en los hechos son de carácter bastante diverso, y no son demasiado abundantes. Contamos con una relación pormenorizada, con una carta literaria y con dos escritos de carácter memorialístico, donde este encuentro se menciona de pasada o de forma elíptica. Son textos redactados también en momentos no siempre coincidentes, que van desde el relato efectuado al calor de los hechos hasta una rememoración tiempo después, con la perspectiva que dan los sucesos posteriores. Es difícil, por tanto, establecer una comparación estricta, aunque su consideración conjunta muestra bien la variabilidad de la representación y de la memoria de Worms.

Comencemos por la relación que acabo de mencionar, y que es probablemente el testimonio redactado con una mayor inmediatez. Se trata de una narración pormenorizada, presentada casi a modo de diario, que se detiene especialmente en las dos jornadas de la comparecencia de Lutero (17 y 18 de abril), en la declaración de Carlos V del día 19, y de forma más breve en los sucesos siguientes hasta la salida de Lutero y las noticias posteriores sobre su secuestro y los responsables del mismo, cuyo propósito y significado se conoce solo el 16 de mayo. Un relato escrito probablemente en diversas fases, que se cierra en todo caso el 16 de mayo, y que por tanto fue compuesto al hilo de los hechos. Esta relación se ha transmitido de forma manuscrita, y ha llegado hasta nosotros al menos en cuatro testimonios: París, Affaires Étrangères, Espagne, 217 y Madrid, Instituto Valencia de Don Juan, ms. 26-I-23 (ambos de mediados del siglo xvI),

2. El tema que me propongo ha sido abordado de forma extensa y monográfica en dos importantes estudios, a cargo de Pfandel (1930-1931) y Goñi Gaztambide (1983). Menciono otros estudios más puntuales a lo largo del trabajo. 
y Londres, British Library, Egerton 307, y Madrid, Biblioteca Nacional, 7084 (los dos del siglo XVII). Aunque la relación no lleva en ningún caso indicación de autoría, el primer editor, Adolf Wrede, que ofreció una transcripción incompleta del texto a partir del ms. Egerton 307, sugirió que podría haber sido escrita por el jurista y consejero real Lorenzo Galíndez de Carvajal, que acompañó a Carlos en aquella jornada. Esta hipótesis fue formulada en función de que el texto en el ms. Egerton 307 se incluye en una miscelánea que contiene otras piezas de carácter histórico o jurídico expresamente firmados por Galíndez. ${ }^{3}$

Puede decirse ahora que, con la excepción del testimonio hoy en el Instituto Valencia de Don Juan, todos los demás exhiben la misma agrupación. Este último ejemplar consiste en una variada miscelánea de tipo documental, pero los dos otros dos proceden también de misceláneas que, con diversos matices, guardan un estrecho parentesco con la de Egerton 307. El ms. BNE 7084 es un ejemplar muy similar, aunque no sabemos si puede establecerse una relación directa. El caso de los folios hoy en Affaires Étrangères es más interesante, pues también nos ilustra sobre los entornos de difusión de este texto. No hay duda de que esos folios fueron arrancados de un manuscrito más extenso, y hoy podemos afirmar sin duda que proceden del ms. BNE 1752, donde faltan justamente los folios actualmente en los archivos parisinos. La letra es la misma, la coincidencia en la foliación es estricta, y el último folio hoy en París se continúa sin rupturas en el manuscrito de la BNE. Este ejemplar perteneció además al historiador Ambrosio de Morales (1513-1591), de cuya mano es la rública que presenta el texto de la relación, y que también introdujo algunas otras anotaciones en el resto de BNE 1752. Pues bien, este ejemplar es igualmente una miscelánea que en su primera parte, la que incluye nuestro texto, agrupa un conjunto similar de textos de Galíndez de Carvajal, aunque con algunas diferencias frente a Egerton 307 y BNE 7084. La coincidencia de la presentación del texto en estos tres casos refuerza por tanto, a mi juicio, la posible autoría de Galíndez de Carvajal, aunque ciertamente carecemos de datos externos y objetivos que permitan asentarla.

Sea como fuere, encaja perfectamente en el marco historiográfico en el que se nos presenta, después del memorial de Galíndez sobre el reinado de los Reyes Católicos y los primeros pasos del gobierno de Carlos V, y detrás de algunos documentos y pareceres de esos primeros ańos, y por tanto dentro de un conjunto de piezas destinadas a dejar memoria de algunos hechos especialmente relevantes, incluso para servir como material para un futuro cronista. En este sentido, que uno de los usuarios posteriores haya sido un historiador como Morales no tendría nada de sorprendente. Sin embargo, lo cierto es que, como veremos, esta relación parece haber sido desconocida para todos aquellos que escribieron sobre

3. Wrede (1896: 652); véase también Pfandl (1930-1931: 493-496). El ejemplar en París, Affaires Étrangères, Espagne, 217 fue editado por Morel-Fatio (1914). Sobre el que se custodia en el Instituto Valencia de Don Juan llamó la atención Redondo (1965: 119, n. 1). 
Worms, pues no dejó huellas en ninguna obra posterior. Tiene una orientación eminentemente informativa, que se caracteriza por una focalización estricta sobre los hechos, sin contextualización de ningún tipo, tanto sobre el problema luterano, como sobre las propias gestiones para lograr la presencia de Lutero en Worms. Se abre directamente con la comparecencia de este el día 17, y tiene un carácter fuertemente descriptivo, tratando de dar cuenta de todos los detalles relevantes de la actuación de Lutero ese día y el siguiente. Recoge luego la declaración de Carlos $\mathrm{V}$ del 19 de abril, y la última sección, más rápida, resume de forma sintética los sucesos más relevantes que siguieron a la comparecencia de Lutero y la reacción del Emperador. Al margen de su horizonte descriptivo, es indudable que se trata de un texto escrito por un espańol, como muestra su atención por la reacción de los escuderos españoles después de la intervención de Lutero el 18 de abril, o la inclusión de la noticia de la llegada de una carta del Consejo de Estado animando al Emperador a combatir las opiniones luteranas.

Vale la pena citar el primero de estos pasajes, porque muestra bien el clima de tensión y enfrentamiento en que tuvieron lugar las sesiones, y porque probablemente es indicio de una reacción que supera el perímetro de los caballeros directamente aludidos:

Y toda la otra gente y el dicho Lutero, alegre y acompañado de muchos Alemanes que le llevavan sobarcado, salió de palacio. El qual y ellos, alçados los bracos y meneando las manos y dedos a la forma que los Alemanes tienen, quando rronpen lanças, en señal de vitoria, le llevaron a su posada, y a la salida de palacio los mocos d'espuelas de los Españoles, que estavan esperando a sus amos a la puerta, dieron grita diciendo: al fuego! al fuego! ${ }^{4}$

Ahora bien, sea por la naturaleza del texto, escrito casi a modo de diario, o sea por una intención deliberada, lo cierto es que la relación no permite por sí misma entender el conflicto que en ella se refiere, al privar al lector de todo tipo de contextualización, En sintonía con ello, no hay en esta pieza ningún propósito explicativo, pues apenas se explicitan las motivaciones de las partes. Solo en un momento, hacia el final de la relación, cuando se refieren brevemente las deliberaciones que se tuvieron con Lutero después de su comparecencia, se afirma que, según algunos, él mismo aseguró que no podía retractarse puesto que estaba comprometido con algunos que querían indisponer a los cristianos contra el Papado. En consonancia con todo ello, la relación termina de un modo abierto, anunciando medidas del Emperador antes de salir de Worms, que ya no se llegan a incluir.

Se trata, pues, casi de un fragmento, de una viñeta eminentemente descriptiva, focalizada estrictamente sobre los días 17 y 18 de abril, con unas breves notas 
en torno a los sucesos posteriores. Quizá su carácter se relacione con su naturaleza subsidiaria, es decir, con el propósito de servir a una historia posterior, más amplia, pero también puede entreverse en ello la dificultad o la reticencia entre buena parte de los historiadores e intelectuales del momento para ofrecer una contextualización de la actuación de Lutero. Rasgo que no nace necesariamente de un desconocimiento, sino tal vez de la decisión de no introducirse en los problemas doctrinales y eclesiásticos que todo el asunto implicaba. En este sentido, veremos que los textos fluctúan entre aquellos que poseen un componente reflexivo, bien sobre Lutero, bien sobre el Emperador, y aquellos otros que sin dejar de mencionar los hechos pasan sobre ellos de forma bastante expeditiva.

En tal sentido, el siguiente texto constituye en buena medida el reverso de la relación manuscrita que acabamos de ver. Se trata de las dos cartas enviadas por Alfonso de Valdés a Pedro Mártir de Anglería, y que este último inserta en sendas cartas suyas remitidas a otros corresponsales. Ambas misivas se singularizan desde el punto de vista de la difusión, al ser los únicos textos impresos entre los escritos en época del Emperador. En efecto, Mártir de Anglería incluyó sus epístolas, con la copia de las cartas de Valdés en su interior, dentro de su Opus epistolarum, publicado en Alcalá en $1530 .{ }^{5}$ Y esto hubo de favorecer su influencia en otras obras, como veremos a continuación.

Las dos cartas de Valdés componen un díptico fuertemente trabado, dentro del cual la primera se centra en el origen y primeros pasos de las acciones y propuestas luteranas, y la segunda se ciñe específicamente a la descripción e interpretación de la Dieta de Worms. La primera está fechada el 31 de agosto de 1520, aunque debe ser probablemente algo posterior, ya que se cita el escrito luterano De la cautividad de Babilonia, que se publicó a comienzos de octubre de ese ańo. La segunda lleva fecha del 13 de mayo de 1521, y en este caso no hay motivos para retrasar esa data, de modo que habría sido escrita al calor de los hechos, contemporáneamente a la relación anónima que hemos visto antes. El hecho de que se trate de dos cartas de Valdés incluidas en sendas misivas de Mártir de Anglería y de que tengan una clara continuidad temática, narrativa e incluso conceptual hace difícil analizarlas por separado, y de hecho quienes se valieron de ellas las consideraron conjuntamente, asumiendo la narración de Valdés e incorporando datos de ambas. La primera carta, la más extensa de las dos, proporciona un contexto histórico y conceptual que permita dar una interpretación del problema, y también una valoración sobre las posibilidades y los límites de lo acaecido en la Dieta de Worms. En este sentido, Valdés propone una visión de las posturas luteranas y de su éxito en función de varios factores:

5. Mártir de Anglería (1530: fols. 157v-158r y 172r-v). La obra se reimprimió en 1670, pero carecemos de una edición moderna. Existe, sin embargo, una traducción de López de Toro, por la que cito a continuación: Mártir de Anglería (1953-1957). Sobre las cartas de Valdés puede verse, además de los estudios de Pfandl y Goñi Gaztambide, González Novalín (1981: 190-192). 
las mezquinas luchas entre frailes (dominicos, gestores y defensores de las bulas, y agustinos, a los que pertenece Lutero), la tensión entre Federico, duque de Sajonia y Alberto, arzobispo de Maguncia (1490-1545), la opulencia de Roma y su temor a un concilio, y finalmente la obstinación de Lutero. En toda su valoración, se trasluce una clara apreciación del conflicto en clave erasmista, tanto desde un punto de vista retórico (con su apelación a los frailes), como por la más o menos explícita crítica a Roma o la defensa de un concilio como la única vía para evitar la ruptura dentro de la cristiandad ${ }^{6}$. También, al igual que Erasmo, Valdés concede un papel relevante a Carlos V, como aquel que puede garantizar el justo desarrollo del concilio.

La segunda carta se centra específicamente en el episodio de Worms. Proporciona una descripción esencial de la comparecencia de Lutero los días 17 y 18 de abril, y muestra la negociación posterior con Lutero, sin ningún resultado, y también las discusiones dentro del círculo imperial en torno a la redacción y publicación del Edicto antiluterano. La conclusión de Valdés es profundamente pesimista, y contrasta con la opinión de otros para los cuales la respuesta de Carlos V surtiría un efecto decisivo:

Entonces el César [...] dado un gravísimo edicto contra Lutero, los luteranos y sus escritos, mandó quemar con la mayor pompa y aparato cuantos libros de Lutero se encontraron aquí, a fin de que todas las ciudades de Alemania siguiesen el mismo ejemplo. Aquí tienes ya el fin, como algunos quieren, de esta tragedia; pero yo me persuado que no es el fin, sino el comienzo de ella. ${ }^{7}$

Valdés relata entonces que los libros de Lutero se siguen vendiendo y comprando como antes, incluso con la presencia del Emperador, para reflexionar que en su ausencia el problema no haría sino agravarse. La carta se cierra de forma sombría, presentando una posible solución como algo que ya se ha dejado escapar, como una ocasión perdida, y remitiendo a la providencia divina el que pueda evitarse «la perdición de la república cristiana». ${ }^{8}$

Las cartas de Valdés son un testimonio elocuente de la preocupación por el problema luterano en el entorno del Emperador entre 1520 y 1521, de la opinión que veía con buenos ojos su implicación, y de una postura que apelaba a una gestión del conflicto que lo canalizase a través de un concilio. Y el tono diferente de las dos cartas responde bien a su cronología, y a la evolución de las impresiones que desde Erasmo y los intelectuales próximos a él se fue produciendo en esos dos años. Así, todavía a fines de 1520 existía la esperanza en que la intervención de

6. Para la posición de Erasmo en el contexto de la Dieta de Worms, ver Tubau (2013: 65).

7. Mártir de Anglería (1953-1957: IV, 164).

8. Mártir de Anglería (1953-1957: IV, 165). El 25 de febrero de 1521 escribía Erasmo a Nicolaas Everaerts: «Sed ipse [Lutero] seipsum suis telis conficit. Hec igitur fatis arbitror relinquenda». Aquí encontramos ya esa apelación al destino o a la Providencia. Véase además Tubau (2013: 64-65). 
Carlos V, su influencia sobre los príncipes electores, y una actitud no abiertamente hostil frente a Lutero, que se aviniese a escucharle, pudiesen abrir algún tipo de resquicio, por pequeño que fuera, para intentar un acercamiento. Pero estas perspectivas se fueron alejando cada vez de forma más evidente a partir de la publicación del escrito De la cautividad de Babilonia, y de la radicalización de las posturas luteranas. En este sentido, la crudeza con la que Valdés presenta la ineficacia del Edicto imperial es similar a aquella con la que había presentado la de las bulas papales, al tiempo que ponía de manifiesto la magnitud de un problema cuya resolución solo parecía estar en manos de Dios. Este último punto es interesante por cuanto apunta a que la focalización de la mirada de Valdés está menos en la persona de Lutero que en el conflicto mismo y en su resolución, para lo cual tratan de identificarse causas y responsabilidades varias, y se requiere en todo momento una actitud comprensiva y activa de la Iglesia romana.

Los otros dos textos de tipo testimonial que mencionaba al principio son de carácter muy diferente, y en ellos la presencia de Lutero y de Worms se ciñe a una rápida (y en un caso elusiva) referencia. Se trata de las Memorias de Sancho Cota, que terminan de forma abrupta en 1538, y de las Memorias de Carlos V, escritas al final de su reinado. En ambos casos, el episodio que aquí nos interesa no se presenta aislado o con una focalización específica, sino que lo hace dentro de un relato más amplio sobre las acciones del Emperador. Sancho Cota (c.1480-1546) se refiere en varias ocasiones a Lutero, aunque de forma muy sucinta, como cuando alude al comienzo de su notoriedad. ${ }^{9}$ Por lo que hace a la Dieta de Worms, su testimonio es interesante por cuanto sugiere el especial interés que Carlos $\mathrm{V}$ habría puesto en este problema, y por su alusión al planteamiento en la Dieta de ciertos españoles. Veamos el pasaje completo, que no es demasiado conocido:

Antes que partiese, enbió a dezir a Luterio, que estava en Alemaña, que le rogava que viniese a fablar con él y le prometía que vernía seguro y bolvería sin que ninguno le fiziese mal. El qual Luterio vino (a Bruselas borrado) y fabló al enperador. El qual le rogó que se quitase de su mala seta y le puso muchos maestros en santa teología que disputaron con él y nunca le pudieron convertir. Algunos espańoles uvo que le quisieron matar, mas no osaron porque el enperador le avía dado su palabra. E así se fue con su mala opinión. ${ }^{10}$

Es evidente que en el relato de Cota hay ya una cierta estilización, que lleva a reducir el episodio a los personajes de Carlos y Lutero, y a exagerar la iniciativa del primero. Pero el cuadro general es esencialmente correcto, y dentro de él destaca el deseo de algunos españoles de asesinar a Lutero, un motivo que, con variaciones diversas, veremos aparecer en otros textos. 
Las referencias en las Memorias de Carlos V son también muy fugaces, aunque no están desprovistas por ello de interés. En el texto se habla de Lutero justamente en relación con el comienzo de la Dieta de Worms, aunque sin aludir en ningún momento a la comparecencia del agustino, estableciendo una sincronía entre la herejía luterana y la guerra de las Comunidades:

E teve a primeira diera en Vormes, que foi a primeira vez que entrou em Alemanha, e pelo Rin, e neste tempo começaram á pullular as heregias de Luthero em Alemanha, e as Comunidades em Hespanha. ${ }^{11}$

La narración sobre Worms no incluye ninguna referencia sobre Lutero, pero resulta significativo el comentario que se efectúa al hablar de su cierre, como indicando que la Dieta había debido clausurarse por deseo ajeno al Emperador, y sin poner en marcha las medidas que habría querido llevar a cabo. Menciona las guerras iniciadas por el rey de Francia, y concluye:

Pola qual causa sua Mag. foi forçado accabar a d. Dieta mais como pode que como desejava e determinava fazer, e assi se partio para resistir aquellas guerras. ${ }^{12}$

Aunque en esta mención no queda claro si ese precipitado final y las nonatas medidas tienen que ver con el problema luterano, es indudable que pasado el tiempo la Dieta de Worms acabó vinculada a este asunto, de modo que ello es muy probable. Y de ser así, mostraría que en la memoria del Emperador el episodio de Worms quedaba también como una ocasión perdida, aunque en este caso ello hubiera sido debido a las hostilidades del rey de Francia, y no tanto a la actitud del propio Lutero. No parece que pueda verse aquí un deseo de exculpar a este último, o disminuir su responsabilidad, sino más bien una percepción según la cual se podría haber hecho algo más, por encima o al margen de Lutero, de no haber sido por la propia desunión de la cristiandad en el terreno político.

\section{Worms en la historiografía quinientista}

Si los textos testimoniales que hemos visto hasta ahora ponen de manifiesto una cierta dispersión, otro tanto ocurre en las obras historiográficas sobre el reinado de Carlos V compuestas a lo largo del siglo xvi. Dejando a un lado los textos parciales, o aquellos que se centran fundamentalmente en los hechos militares de Carlos, el episodio de Worms figura en todos ellos, aunque con alguna elocuente excepción. No realizaré un comentario detenido de cada obra, que ocuparía sin duda un espacio excesivo. Plantearé, en cambio, una visión general sobre las diversas obras, atendiendo a su cronología y sus rasgos más relevantes,

11. Morel-Fatio (1913: 190).

12. Morel-Fatio (1913: 192). 
para concentrarme finalmente en el texto inédito de Juan Páez de Castro, perteneciente a una historia emprendida bajo Felipe II, que quedó inconclusa a la muerte del autor. ${ }^{13}$

Veamos, en primer lugar, las dos historias compuestas todavía en vida de Carlos V, es decir, las firmadas por Pedro Mexía, escrita hacia 1550, y la de Alonso de Santa Cruz. La primera corresponde a una crónica incompleta, que alcanza solamente hasta 1530, aunque en la parte que llegó a escribirse ofrece una redacción sustancialmente terminada. La de Santa Cruz, escrita en fechas cercanas, hacia 1551-1553, es una historia más amplia, casi completa, que ofrece una de las pocas visiones de conjunto sobre Carlos $\mathrm{V}$ antes de la compilación de Prudencio de Sandoval, a comienzos del siglo XviI. Ahora bien, tanto la historia de Mexía como la de Santa Cruz no alcanzaron a imprimirse en su época, y permanecieron inéditas hasta el siglo Xx, un destino bastante común en las historias de Carlos V, como iremos viendo. Aunque son textos con diferencias evidentes, y que no exhiben conexiones entre sí, une a estas dos historias el hecho de que al tratar sobre la presencia de Lutero en Worms ambas tienen como fuente básica las cartas de Valdés que hemos comentado en el apartado anterior, tanto la dedicada específicamente a Worms, como aquella en que traza los orígenes de las enseńanzas luteranas, y que sirve para contextualizar la comparecencia de Lutero ante el emperador.

Con todo, por debajo de ese uso común, se perciben algunas diferencias tanto en el tratamiento de las cartas como en la adición de información suplementaria, matices que es preciso comentar, aunque sea brevemente. En el caso de Mexía, se ciñe de forma bastante fiel a la información presentada por Valdés, aunque con algunas pequeñas variaciones: por un lado, tiende a diluir (aunque no las elimina) las notas críticas hacia el Papado, y por otro caracteriza en varios momentos a Lutero como un avatar del demonio, enfatizando de este modo su presentación negativa (escribe, por ejemplo: «y como el demonio estaua ya en el coraçón de Lutero»; y más adelante: «él, con la soberbia de Lucifer que traya en el alma y en el coraçón, rrespondió que él no pensaua rrebocar lo que tenía escrito"). ${ }^{14}$ Sin embargo, estas últimas alusiones no dejan de tener un cierto aire tópico, que no permiten detectar una sustancial modificación del retrato ya ofrecido por Valdés. Por otro lado, Mexía divide la información sobre Lutero en dos momentos diferentes, contextualizándola cronológicamente. En este sentido, Mexía retrotrae el origen de las enseñanzas luteranas al año 1518, situando en esa fecha el texto De la cautividad de Babilonia, lo que en cierta medida le permite atribuir la extensión de los seguidores de Lutero a la ineficacia de

13. No existe una buena exposición general sobre la historiografía del siglo xvi. Puede verse, en todo caso, el panorama de Sánchez Alonso (1944), y los estudios más recientes de Cuart Moner (2004) y Kagan (2010).

14. Mexía (1945: 102 y 232, respectivamente). 
Maximiliano, quien no acertó a atajar este conflicto en la Dieta de Augsburgo, celebrada ese año, con la presencia del agustino:

De manera que este fue el principio del açote y plaga que la cristiandad a padeçido, y dello se a seguido lo que después avemos visto y en sus lugares iremos tocando. En lo qual no se puede negar que huvo negligençia y descuydo en los principios; porque si el emperador Maximiliano, de propósito y con gran determinación, como convenía, en estas Cortes y antes dellas, pusiera el remedio que convenía, por ventura no viniera las cosa a lo que después vimos. Pero ello pasa ansí como tengo dicho, por nuestros pecados. ${ }^{15}$

En este pasaje podemos ver ya implícitamente una de las preguntas que se suscitan en los textos históricos sobre el Emperador, es decir, si este pudo haber hecho algo más para evitar la expansión del luteranismo, que en cierto modo Mexía responde desplazando la responsabilidad hacia su predecesor Maximiliano.

Es interesante, por lo demás, notar que Mexía debía de tener algún conocimiento de la doctrina luterana, y quizá haber leído alguno de los textos del propio Lutero, pues al citar, tomándolo de Valdés, el título De la cautividad de Babilonia, lo glosa de la siguiente manera:

Y despertando las heregias de Juan Huss, antiguo hereje de Bohemia, contra la beneraçion de las imágenes, contra las santas reliquias y el sacramento de la confesión, y las demás, con otras que añadió, que hoy son notorias y sauidas, se atreuió a las firmar y defender. ${ }^{16}$

Este conocimiento se observa también en el texto de Santa Cruz, y quizá permite atisbar algo sobre la difusión de textos luteranos en la Sevilla de mediados del siglo XVI, donde vivían los dos historiadores en el momento en que componen sus obras.

En cuanto a las informaciones de tipo anecdótico o histórico que añade Mexía, apenas puede citarse la referencia a la idea que circuló en Worms en el círculo imperial de prender y quemar a Lutero, idea que no contó con la aprobación del Carlos V:

Y algunos tubieron por opinión que fuera bien que a vn tan desbergonçado herege no se le guardara la seguridad que se le auía dado, y que fuera allí presso y quemado; porque se presumía que faltando la caueça y mobedor, que hera él, con más facilidad se rremediara lo demás. Pero el Emperador, como aquel que no quería faltar la fe, aunque fuese a quien no la tenía, ni jamás la ha faltado ni rronpido, no estubo en lo hazer. ${ }^{17}$

15. Mexía (1945: 103-104).

16. Mexía (1945: 103).

17. Mexía (1945:232-233). 
Como hemos visto, algo similar sugiere Cota, aunque en Mexía el proyecto no se circunscribe a los consejeros españoles, sino que se le da un alcance más global, sirviendo para mostrar la lealtad y nobleza del Emperador, que queda por tanto como una suerte de antítesis de Lutero.

El texto de Santa Cruz es mucho más rico en innovaciones y desde luego más interesante, aunque aquí no le pueda hacer justicia. El historiador privilegia el eje temático sobre el cronológico, y en consecuencia agrupa toda la materia relacionada con Lutero y Worms en dos capítulos sucesivos, en los que trata, primero, del personaje y de sus planteamientos, y después del episodio de Worms. Aunque la fuente fundamental viene constituida de nuevo por las cartas de Valdés, Santa Cruz las desborda ampliamente, sobre todo por lo que hace a la descripción de Lutero y de sus ideas, de las que ofrece un resumen apresurado, pero que pone de manifiesto el contacto con el luteranismo. Llama la atención la caracterización ambivalente del agustino, a quien considera «maldito", gran hereje, pero también un individuo fascinante, «hombre astuto y agudo", y dotado de una incomparable elocuencia. Esta ambivalencia confiere al retrato de Santa Cruz una complejidad que en vano buscaremos en otros textos hispánicos contemporáneos. Al resumir las enseñanzas de Lutero, parece claro que el historiador conocía el escrito De la cautividad de Babilonia, y es muy probable que hubiera leído otros opúsculos luteranos, al margen de que algunas ideas puedan haberle llegado oralmente. Santa Cruz incurre en algunos errores cronológicos, como adelantar las opiniones rupturistas de Lutero al año 1515, pero no es menos cierto que la cronología juega aquí un papel secundario, y que lo más importante es la comunicación del enorme impacto producido por la predicación y los escritos de Lutero, que obtuvieron innumerables seguidores:

Y estas y otras muchas cosas dijo y predicó y escribió el maldito hereje Fray Martín Lutero, y no es nada decirlas y escribirlas, sino que tuvo tan gran crédito en todos los pueblos de Alemania, que absolutamente todo lo que él decía ellos creían, y todo lo que él mandaba ellos cumplían, y así ninguna herejía grande o pequeña, extraña o común, tuvo o dijo o escribió Fray Martín que luego no la pusiesen por obra todos los pueblos de Alemania, con los cuales tuvo tanto crédito que si del todo intentara destruir la ley de Cristo se saliera con ello. ${ }^{18}$

Santa Cruz reconoce, como Valdés, el fundamento de ciertas críticas luteranas al Papado, en particular las que se relacionaban con la codicia y la simonía, y en este sentido es muy probable que pueda considerarse al historiador, cuya formación desconocemos casi por completo, como un erasmista rezagado. En el episodio de Worms, el relato de Santa Cruz se caracteriza por dar la voz a Lutero en su segunda comparecencia ante Carlos V, ofreciendo una suerte de resumen

18. Santa Cruz (1920-1925: I, 409). 
de lo que habría sido su discurso ante el Emperador, aunque esta segunda parte es sin duda menos original que la anterior ${ }^{19}$.

En conjunto, en el texto de Santa Cruz acaba por tener una mayor relevancia el propio personaje de Lutero y sus enseñanzas, por encima del episodio de Worms y de su coincidencia con Carlos V. Es en el primero de estos ejes temáticos en el que el historiador centra sus innovaciones sobre las cartas valdesianas, efectuando una suerte de síntesis de las doctrinas luteranas, y ofreciendo una breve biografía de Lutero. Aunque pueden detectarse aquí y allá diversas inexactitudes, ello no debe impedir reconocer el interés y la originalidad de Santa Cruz en este punto, ya que el resto de obras tienden a pasar de puntillas por la propia personalidad y obra de Lutero, y cuando no lo hacen así la orientación está mediatizada ya por la polémica antiluterana, como veremos en las historias de Gonzalo de Illescas y Prudencio de Sandoval.

De las obras terminadas o producidas en la época de Felipe II, y dejando a un lado por ahora el texto de Páez de Castro, me detendré brevemente en dos, de muy diferente signo. La primera es el De rebus gestis Caroli V, de Juan Ginés de Sepúlveda, comenzada a escribir bajo Carlos $\mathrm{V}$ y terminada ya en época de su hijo. Por lo que respecta al episodio de Worms, caracteriza a la historia de Ginés de Sepúlveda el haberlo ignorado completamente, sin mencionarlo siquiera en su obra, a pesar de que el historiador, que había polemizado con el luteranismo, no podía desconocerlo. Si siempre es difícil, cuando no imposible, interpretar un silencio en una obra histórica, tal vez pueda ligarse en nuestro caso a la posición crítica que el cronista oficial manifiesta en su obra por la labor imperial de Carlos V, de la que derivaba su implicación directa y prolongada en el conflicto luterano. ${ }^{20}$ Sea como fuere, es también una forma de no conceder apenas espacio en el texto histórico al propio Lutero, que solo aparece fugazmente en contadas ocasiones.

El segundo texto al que quisiera referirme es la Historia pontifical y cathólica de Gonzalo de Illescas, donde figura el episodio de Worms, aunque aquí con una contextualización diferente, no dentro de una crónica sobre el reinado de Carlos V, sino dentro de una historia de los papas. La sección que nos interesa figura dentro de la biografía de León X (1513-1521), y aparece en la segunda parte de su Historia pontifical, publicada en 1573. En este caso, el relato procede de la literatura antiluterana, ya que la sección sobre Lutero es prácticamente una traducción de la biografía escrita por Juan Cocleo (Cochlaeus), sobre la cual Illescas enfatiza los rasgos negativos del personaje. Al margen de ser uno de los pocos textos históricos sobre Lutero en romance impresos en el siglo xvI, el texto de Illescas es notable también por su influencia, ya que Prudencio de Sandoval,

19. Santa Cruz (1920-1925: I, 414).

20. Cuart Moner (2004) ha destacado sagazmente las reticencias de Ginés de Sepúlveda ante la política imperial. 
en su historia de Carlos V publicada por primera vez en 1604, lo copió a la letra, prácticamente sin añadir nada, a excepción del Edicto imperial promulgado al final de la Dieta de Worms. Por esta vía, el relato de Illescas (y en sustancia de Cocleo) se consolidó como la visión oficial sobre Worms en la historiografía española de fines del siglo XVI en adelante, cerrando con ello un largo periodo de percepciones más matizadas y diversas.

Detengámonos, para terminar, en el relato que ofrece Juan Páez de Castro en sus apuntes para una historia de Carlos V, que se conservan autógrafos en El Escorial (ms. \&-III-10). Como es sabido, Páez de Castro es uno de los humanistas españoles más destacados de mediados del siglo XVI, a quien se nombró cronista oficial poco después de la muerte de Florián de Ocampo, en 1556. Páez de Castro recibió materiales que habían pertenecido a Ocampo, y reunió a su vez textos que deberían servirle para su obra. No parece que llegase a terminar la historia de Carlos $\mathrm{V}$, pero en el mencionado manuscrito escurialense se conserva una suerte de resumen o de índice, que podemos caracterizar también como un proyecto $^{21}$. Aquí se encuentra una narración sobre la Dieta de Worms, que, por ser desconocida, transcribo por extenso:

[fol. 42r] 1521. El duque Federico acompańando al Emperador a la dieta de Vormes procuro que el emperador dixesse que queria que viniese alli Lutero. Y assi le embio a llamar, escriviendole a VI de março que le dava licencia para que pudiese venir y tornar, y para esto le embio un salvo conduto. Llego a Vormes a xvi de abril. Hablo Eccio juriscons. en nombre del Cęsar y preguntole si queria defender lo que en sus libros escrivio; pidio termino y dieronle un dia. $Y$ venido el termino dixo muchas desvergüenças; tanto que el Emperador escrivio una carta en que dezia que el era obligado a defender la religion cristiana y la Iglesia Romana y pues Luth. se apartava della que el hallaria camino de le castigar, que agora por causa del salvo conduto le dava licencia que se fuese luego ly que dentro de XXI dias saliese del Imperio/. Tratose en consejo si se le guardaria la fe, y si no fuera por el palatino y otros no se la guardara, y ovieran hecho muy santamente y libraran al mundo de tanto mal como aquel vellaco ha causado. [fol. 42v] Jo. Wiclero fue el que tuvo las mas heregias que despues resucito Luth. fue de Inglaterra y vivio el año 1393, y sus escritos llegaron a Bohemia a la universidad de Praga, donde estava Jo. Hus el qual defendia las heregias de Wicleo; mandole citar el papa Alex. V y no oso parecer y asi fue condenado. Era un tiempo muy turbulento porque avia scisma y los cardenales avian elegido tres papas: a Gregorio XII, y a Benedicto XIII, y a Joan XXIII. El papa Juan convoco un concilio en Constancia; fue llamado alli con salvo conduto pero no se le guardo y el emperador Segismundo le mando quemar despues de condenado y las cenizas se cesaron en el Rin, y lo mesmo hizieron con Geronimo de Praga. En este concilio estuvo el Emperador y III electores Luis Palatino, Rodolfo de Saxonia, Feder. de Brandeburg. tres patriarcas: el de Aquileia,

21. La labor historiográfica de Páez de Castro está aún por estudiar. Véase el planteamiento general de Ostenfeld-Suske (2016), donde no se menciona, sin embargo, el manuscrito del que trato aquí. 
el de Antiochia, el de Constantin. y XXIIX cardenales obispos CLV. Condenaron a Wiclero y mandaron que desenterrasen su cuerpo en Inglaterra y le quemasen. Si esto se hiziera con Luth. todo el mundo estuviera ya sosegado como se sosego entonçes. Al fin renunciaron los tres pontifices y eligieron a Martino V. Por causa destos hereges justiciados se levanto un Zischa en Bohemia y ovo guerra y persecucion contra los ecclesiasticos. Hizo la universidad de Paris una condenacion de las obras del malvado Luh. muy docta y pia. Hizo este ańo liga el papa Leon y Fran. con los suyzos y embio el Papa por gente; estorvavalo Zuinglio gran herege pero no salio con ello. Solos los taguinos le siguieron y juraron de no ir jamas con sueldo de principe fuera de sus tierras. Nacio Carlos en aquel año hijo del rey, y embiaron los suyzos embaxadores que fuessen sus padrinos en su bautismo. El emperador siendo de XXI años cumplidos condeno al heresiarca Luth. a IIX de mayo haziendo una provision en que cuenta la obligacion que el tiene de hazer esto y las vellaquerias de Luth. y los cumplimientos que con el se hizieron assi de parte del Papa como suya. Cuenta la rabia de aquel herege, y dize que hombre tan soberbio y cruel no es hombre sino demonio en figura humana. Prohibe sus libros, y manda a los libreros que no los impriman so graves [fol. 43r] penas. Da facultades a qualquiera que le pudiese prender que se le trayga para castigarle.

Como puede apreciarse, la narración de Páez de Castro es independiente de todos los textos que hemos visto hasta ahora. Se distingue principalmente por la contextualización de la figura de Lutero en relación con herejes anteriores (en particular Wyclif y Huss), que ocupa la mayor parte del relato. Tampoco se proporciona una información demasiado precisa o desarrollada sobre la propia comparecencia de Lutero, sino que se sugiere que se debería haber tratado a este individuo como se hizo anteriormente con otros herejes.

Curiosamente, a pesar del decidido y abierto posicionamento antiluterano que muestra Páez de Castro, lo cierto es que se basa en una obra de orientación luterana, que obtuvo un inmediato éxito e impuso su autoridad incluso entre los eruditos católicos. Me refiero a Juan Sleidan (1506-1556), y a sus De statu religionis et reipublicae Carolo V Caesare commentarii, publicados en 1555. Esta obra alcanzó una inmediata resonancia, y fue traducida al francés y al inglés muy pronto. También muy pronto, junto al resto de la producción del autor, quedó prohibida por la censura romana, ya que Sleidan aparece entre los autores prohibidos en el índice de 1559. Con todo, varios intelectuales españoles, entre ellos el propio Páez de Castro, manifiestan su interés en el texto antes de esa fecha. Así, en una carta a Jerónimo Zurita del 12 de julio de 1556, escrita desde Bruselas, le dice:

Un luterano ha publicado una historia que llama De statu religionis sub Carolo $V$; dicen que es bien curiosa en las cosas del imperio desde la coronación de su majestad. ${ }^{22}$ 
El propio Juan Ginés de Sepúlveda tomó a Sleidan como una de las fuentes principales para los hechos del imperio, y en fechas próximas, el 1 de junio de 1557, escribe a su amigo Guillermo van Male este interesante comentario a propósito de Sleidan:

Y antes que nada me ha parecido bien leer los Comentarios de Johann Sleidan, que nuestro amigo Luis de Ávila, Comendador Mayor de la Orden de Alcántara, me ha enviado recientemente, tal como se había ofrecido en tu presencia, para que se los devolviera tan pronto los hubiese leído. Ambos me confirmasteis con seguridad que podrían serme útiles para la revisión de lo que yo mismo había escrito sobre los asuntos alemanes. Me dedico, pues, también ahora con agrado a la lectura de sus Comentarios, en la medida en que la salud me lo permite. No porque comparta sus planteamientos (¿cómo hacerlo, si están viciados por una inclinación impía al bando sedicioso?) o me deleite con su estilo poco cultivado y tan alejado del brillo y la pureza de los mejores escritores antiguos, sino porque parece que fue muy diligente al recordar lo que aconteció en aquellas regiones en este momento, algo de lo cual no tenía yo una idea lo suficientemente clara, al ser tanta la distancia que nos separa. ${ }^{23}$

Aparece aquí un juicio similar al de Páez de Castro, que resalta el interés de la obra de Sleidan en cuanto a los datos, aunque sea reprobable por sus perspectivas o por su ideología. Y resulta interesante porque implica a Luis de Ávila, también historiador, que se nos presenta como inesperado admirador de su obra. Estos dos testimonios dibujan, por tanto, una inicial aprobación y una amplia utilización de la historia de Sleidan.

Sin embargo, no fue esta una posición unánime, o al menos fue variando muy pronto, como deja ver una carta del Cardenal Granvela a Humberto Foglietta, un erudito italiano que había manifestado su interés en escribir la historia de Carlos V. En dicha carta, del 5 de noviembre de 1558, Granvela le previene contra la obra de Sleidan:

V. S. hauerà già inteso il principio della mutationi della religioni fatto da Martin Luthero, et se ne potrà rinfrescar la memoria facendosi legger vn libro francese ch'è stato di nuouo composto da vno in Paregi chi si chiama Fontaine, dottorre theologo, inscrito L'Historia catholica di nostro tempo; et non seguiti lo Sleydano, ch'è falso in infiniti luoghi. Et mi recordo che fra le scritture del Duca Gio. Federico, quando fu preso, trouassimo la soa patente che li fecero li protestanti et vna instruttione con la quale li cometteuano di scriuer la historia come essi voleuano, in fauor loro; et così l'ha fatto, et so che stampata che fu, da principio il nostro Vicencanc. Seld annotò forse da mille passi falsi, et gli scrisse domandandogli per ch'in quelli, scriuendo historia, si fusse alontanato dal vero; ma non gli fece altra risposta se non che così l'haueuano informato li protestanti alli quali serueua. ${ }^{24}$

23. Ginés de Sepúlveda (2007: 365). Otra interesante referencia a Sleidan en la conocida carta a Diego de Neila, algo posterior a la aquí citada; véase Ginés de Sepúlveda (2007: 378-381).

24. Edita esta carta Fernández Álvarez (1958: 714-715). 
Aparece en esta carta una valoración mucho más crítica de Sleidan, como historiador partidista, carente de crédito, en torno al cual se desarrolla además toda una suerte de contra-historia. A ella pertenecerían las notas de Seld sobre el ejemplar de Sleidan a las que alude Granvela (a propósito del cual ignoro si se conserva y se encuentra localizado), y también la propia obra de Simon Fontaine que el cardenal menciona como fuente fidedigna, publicada en 1558, y que lleva el elocuente título de Histoire catholique de notre temps, touchant l'estat de la religion chrestienne contre l'histoire de Jean Sleydan.

Este panorama permite comprender mejor el uso por parte de Páez de Castro de la obra de Sleidan, cuando su visión del conflicto luterano, y particularmente de la Dieta de Worms, es opuesto al que expone su fuente. En este sentido, Páez de Castro se sitúa en esa corriente que valora los datos, aunque deplore la ideología, como hace Ginés de Sepúlveda, y también en la posición adoptada por historiadores como Simon Fontaine, que se arrojaron a escribir una suerte de contra-Sleidan ${ }^{25}$. De hecho, esto último es lo que hace Páez de Castro al tratar sobre Worms, pues si bien toma la contextualización religiosa de su fuente (todo lo relacionado con Wyclif y Huss), en realidad hace funcionar ese contexto en una visión claramente opuesta a Lutero. Ahora bien, parece que ni siquiera esta utilización a contrapelo estaba exenta de problemas, y ya Granvela desaconsejaba su consulta, al existir una fuente que podía suplir de forma menos equívoca los datos históricos, como es Fontaine. Y a medida en que crecía la bibliografía histórica y antiluterana, como con la obra de Cocleo, el texto de Sleidan quedará definitivamente suplantado entre los historiadores católicos, como muestran los ejemplos de Illescas y Sandoval, que he comentado anteriormente.

\section{Conclusiones}

El repaso por las diversas representaciones de la comparecencia de Lutero ante Carlos V en el curso de la Dieta de Worms que podemos encontrar en los textos historiográficos de la España del siglo xvi destaca por la variedad y por la escasa difusión. Esta aparente paradoja — variedad y escasa circulación- probablemente puede vincularse con la reticencia a dar noticia del personaje de Lutero, que algunos de los textos, como las palabras con las que Pedro Mártir de Anglería comenta las cartas de Valdés, ponen de manifiesto. En este sentido, es notable que durante buena parte del quinientos español solo pudiera leerse en letras de molde el texto latino de Valdés. Para cuando se publica la obra de Illescas, que incluye una narración sobre Lutero dentro de la historia de los papas, el cisma abierto por Lutero ya se ha consumado y suscitado una respuesta oficial por parte de la Iglesia católica.

25. Sobre la utilización de Sleidan en ambientes católicos y la aparición de contra-historias como la de Fontaine, véase Kess (2008). 
La variedad de los textos es también fruto de su cronología, y de su ubicación en el decurso de este conflicto religioso. Así, mientras que las obras producidas en época de Carlos $V$ pueden percibirse todavía matices e incluso simpatías por algunas de las críticas luteranas hacia el papado, a partir de mediados del siglo XVI los relatos quedan impregnados por la polémica historiográfica y religiosa, ya sea a partir de las obras de Sleidan o de Cocleo. Este decurso consolida finalmente un relato oficial, creado por Illescas a partir de Cocleo, que se convierte en canónico poco después, y que se impone a través de la imprenta, al ser trasladado literalmente por Sandoval en su historia de Carlos V. Por lo demás, hay que reconocer que la variedad es en general de tono o de orientación, porque los textos destacan por el limitado uso de fuentes y la escasa voluntad de desarrollo. Así, Valdés es la espina dorsal de Mexía y de Santa Cruz, aunque este último amplía el relato en lo relativo al propio Lutero, para ofrecer una imagen equívoca de fascinación y condena, que es tanto más interesante cuanto en ella se transparenta un cierto conocimiento de los textos del agustino y tal vez una recepción oral de tradiciones en torno a él. En época de Felipe II, las historias, como cabía esperar, se alimentan ya de la creciente bibliografía en torno a la historia del luteranismo, aunque lo hacen de modo muy selectivo, apoyándose en los textos esenciales de Sleidan y Cocleo. Es verdad que, en el caso de España, el limitado acceso a la imprenta de los textos históricos no puede achacarse a la representación de Lutero, ya que este ocupa un lugar muy puntual en los textos. Pero no es menos cierto que la historización del conflicto luterano era uno de los aspectos más difíciles y controvertidos de las historias sobre Carlos V, y el episodio aquí considerado acaba siendo también una muestra más de ello. 


\section{Bibliografía}

Cuart Moner, Baltasar, «La larga marcha de las historias de España en el siglo XVI», La construcción de las historias de España, coord. Ricardo García Cárcel, Madrid, Marcial Pons, 2004, 45-126

Domingo Malvadi, Arantxa, Bibliofilia humanista en tiempos de Felipe II: la biblioteca de Juan Páez de Castro, Salamanca, Ediciones Universidad de Salamanca, 2011.

Fernández Álvarez, Manuel, «Las 'Memorias' de Carlos V», Hispania, 18 (1958), 690-718.

García-Villoslada, Ricardo, Martín Lutero, Madrid, Editorial Católica, 19731976, 2 vols.

Ginés de Sepúlveda, Juan, Obras completas. IX, 2: Epistolario. Cartas 76-139 (1549-1567), ed. y trad. Ignacio J. García Pinilla y Julián Solana Pujalte, Pozoblanco, Ayuntamiento de Pozoblanco, 2007.

González Novalín, José Luis, «Pedro Mártir de Anglería y sus 'Triunviros' (1506-1522): nuevas aportaciones al conocimiento de Erasmo y Lutero en España", Hispania Sacra, 33 (1981), 143-197.

Goñı Gaztambide, José, "La imagen de Lutero en España», Scripta Theologica, 15 (1983), 469-528.

Illescas, Gonzalo de, Segunda parte de la Historia pontifical y catholica, Salamanca, Vincent de Portonariis, 1573.

Kagan, Richard L., Los cronistas y la Corona: la politica de la historia en España en las edades media y moderna, Madrid, Centro de Estudios Europa Hispánica, 2010.

Keniston, Hayward, ed., Memorias de Sancho Cota, Cambridge, Mass., Harvard University Press, 1964.

Kess, Alexandra, Johann Sleidan and the Protestant Vision of History, Aldershot, Ashgate, 2008.

Mártir de Anglería, Pedro, Opus epistolarum, Alcalá de Henares, Miguel de Eguía, 1530.

—, Epistolario, trad. José López de Toro, Documentos Inéditos para la Historia de España, 9-12, Madrid, 1953-1957.

Mexía, Pedro, Historia del emperador Carlos V, ed. Juan de Mata Carriazo, Madrid, Espasa-Calpe, 1945.

Morel-Fatio, Alfred, «Le premier témoignage espagnol sur les interrogatoires de Luther à la Diète de Worms en avril 1521», Bulletin Hispanique, 16 (1914), 35-45.

—, Historiographie de Charles-Quint, París, Champion, 1913.

Ostenfeld-Suske, Kira von, "Juan Páez de Castro, Charles V, and a Method for Royal Historiography", Portraying the Prince in the Renaissance: The Humanist Depiction of Rulers in Historiographical and Biographical Texts, ed. Patrick Baker, Ronny Kaiser, Maike Priesterjahn, y Johannes Helmrath, Berlín, De Gruyter, 2016, 363-389. 
Pfandl, Ludwig, «Das spanische Lutherbild des 16. Jahrhunderts. Studien und Vorarbeiten", Histonsches Jahrbuch, 50 (1930) 464-497; 51 (1931) 47-85 y 485-537.

Redondo, Augustin, «Luther et l'Espagne de 1520 à 1536», Mélanges de la Casa de Velázquez, 1 (1965), 109-165.

Sánchez Alonso, Benito, Historia de la historiografia española, II: De Ocampo a Solis (1543-1684), Madrid, Consejo Superior de Investigaciones Científicas, 1944.

Santa Cruz, Alonso de, Crónica del emperador Carlos V, ed. Ricardo Beltrán Rózpide y Antonio Blázquez y Delgado-Aguilera, Madrid, Real Academia de la Historia, 1920-1925, 5 vols.

Tubau, Xavier, Erasmo mediador: política y religión en los primeros años de la Reforma, Valladolid, Universidad de Valladolid, 2013.

WREDE, Adolf, ed., Deutsche Reichstagsakten unter Kaiser Karl V, vol. 2, Gotha, 1896. 
